\title{
SAN MARCOS Y LA CAPACITACIÓN A LAS PYMES EN EL SECTOR MANUFACTURERO DEL PERÚ
}

M.A. Raúl Arrarte Mera*

\author{
RESUMEN
}

\begin{abstract}
Este trabajo de investigación financiado por el Instituto de Investigación de Ciencias Financieras y Contables en el año 2002, fue presentado como «Situación y Perspectiva de las Pymes en el Sector Manufacturero del Perú». Esta investigación está orientada al sector PYMES manufacturero con la intención de recomendar el establecimiento de planes curriculares específicos en la Facultad de Ciencias Contables para preparar especialistas en sistemas de información contable y gerencial para las PYMES; realizar programas de capacitación para los responsables de la dirección; establecer programas de prácticas preprofesionales para los alumnos de Ciencias Contables formando no sólo profesionales al servicio de las grandes empresas públicas y privadas, como lo es a la fecha, sino también a favor de las PYMES contribuyendo con ello a los fines de nuestra Universidad en beneficio de los sectores emergentes del país y al desarrollo económico y social. Buscando simultáneamente generar puestos de trabajo para mitigar la economía de un vasto conglomerado de ciudadanos peruanos desocupados por el proceso de la globalización.

El resultado de esta investigación nos ha mostrado que las PYMES para que puedan afrontar con éxito sus problemas y encontrar soluciones globales necesitan del apoyo no de una Facultad sino del esfuerzo de la Universidad en su conjunto. La participación debe ser multidisciplinaria. En las líneas que siguen presentamos nuestra propuesta.
\end{abstract}

\section{INTRODUCCIÓN}

Un estudio realizado en 1998 , en materia de capacitación y asistencia técnica en nuestro país ${ }^{1}$ pone de relieve los siguientes rasgos, que debemos tener presente al momento de formular programas de capacitación para este sector:
1. Atraso de las PYMES en la formación de los empresarios frente a los demás actores que influyen en el desarrollo empresarial. La diferencias de preparación entre las autoridades públicas, las instituciones de formación profesional y de educación, las ONG's, las

* Profesor Auxiliar de la Facultad de Ciencias Contables

1 Centro de Investigaciones Sociales, Económicas y Tecnológicas-CINCEYT. Análisis de Legislación PYME para un Marco Promotor, Año 1998. Lima-Perú. 
fundaciones, los bancos y los empresarios dificultan la coordinación interinstitucional que conduzca al desarrollo de las empresas con beneficio para la sociedad en general.

Las PYMES están ubicadas en una gran variedad de sectores y subsectores y la población de pequeños empresarios está conformada por personas de diferente nivel cultural. Esta situación determina la presencia de diversa y variada oferta de capacitación.

El nivel de educación de los pequeños empresarios es, por lo general, inferior al de los directivos de empresas medianas. La oferta de capacitación existente no toma en cuenta dicha situación.

El pequeño empresario dispone de poco tiempo para seguir cursos $\mathrm{y}$, en todo caso, su interés está en aquellos rubros que atiendan las necesidades específicas de su empresa.

5. Las instituciones encargadas de la formación, consultora y asistencia técnica a las PYMES, no cuentan, en su mayoria, con personal que posea la experiencia y calificaciones necesarias para atender adecuadamente las necesidades de este estrato empresarial.

6. La mayoría de cursos y programas de formación y capacitación para pequeños empresarios son versiones diluidas o simplificadas de los programas que se ofrecen a directivos de grandes empresas o a estudiantes universitarios de economía y administración.
7. El diseño de los programas es hecho por personas preparadas para brindar servicios de empresas grandes o multinacionales, y, por lo tanto, especializadas en algunos aspectos de la gestión (finanzas, mercadeo, personal, contabilidad, etc.) que poseen un lenguaje muy técnico y poco accesible para los pequeños empresarios.

8. Las metodologías utilizadas siguen enfoques tradicionales de formación y no se adecúan a los niveles de comprensión de las capacidades de los pequeños empresarios, ni se adaptan a los problemas particulares de las PYMES.

Según el Informe Anual del Servicio Nacional de Administración en Trabajo Industrial (SENATI), de 1999, las PYMES, en general, necesitan capacitación en dos grandes áreas que están interrelacionadas:

1) Área Técnica Productiva: Se busca:

- Mejora en la calidad de los productos.

- Mejora en la productividad.

- Mejora en la capacidad de cumplimiento en plazos y volúmenes de entrega.

- Incorporar la aplicación de normas y estándares.

- Mantener las máquinas y equipos en condiciones óptimas de producción.

Desarrollar nuevos productos.

- Aplicar normas de seguridad e higiene industrial en el proceso productivo.

Protección del medio ambiente. 
2) Área de Gestión Empresarial: Se busca:

- Superar las barreras de la informalidad.

- Propiciar una visión de futuro.

- Incorporar criterios de eficiencia y competitividad.

Promover un espíritu creativo para la innovación y el desarrollo.

- Propiciar una cultura de calidad.

- Desarrollar la capacidad de liderazgo, el trabajo en equipo y la estimulación de talentos.

- Valorar la inversión en capacitación continua como una herramienta eficaz para la gestión de la calidad.

La lección que sacamos del análisis de esta investigación, es la necesidad de buscar alianzas estratégicas, de abrir puertas a una reorganización de tipo corporativo y de replantear las asociaciones por ramas, consorcios de exportación, elemento clave para el planeamiento estratégico industrial. $\mathrm{El}$ futuro del éxito de las PYMES descansa en la eficiencia de una alianza ESTRATÉGICA ENTRE EMPRESAUNIVERSIDADES-ESTADO. Sólo un esfuerzo conjunto de estos sectores, que recoja el diagnóstico antes mencionado, hará posible modificar ese archipiélago de pequeñas empresas en sectores planificados y coordinados para satisfacer esa demanda insatisfecha de preparar mano de obra calificada hacia la promoción de exportaciones vía ATPDA.

\section{LO gUE PUEDE HACER LA UNIVERSIDAD NACIONAL MAYOR DE SAN MARCOS}

Después de un largo proceso de investigación, siete meses, tenemos la autoridad suficiente como para proponer las alternativas de solución al problema planteado. $\mathrm{Y}$ éste no es posible, sino al amparo de una estructura organizacional orientada a las PYMES. Nuestra Facultad no la tiene. Nuestra Universidad no cuenta con ella.

La capacitación en la Universidad Nacional Mayor de San Marcos está dividida en tres sectores: Las Unidades de Postgrado para Maestría y Doctorado. Los Centros de Extensión Universitaria y Proyección Social (CEUPS), dedicados a la preparación de cursos cortos y a la actualización para Bachilleres. Y la Gestión en Asesoria Empresarial que es un área no cubierta por el actual Consejo Superior de Investigaciones. La gran debilidad organizacional de estas direcciones es que compiten entre facultades y actúan en forma desarticulada. Un despropósito desde el punto de vista de coordinación administrativa.

Por lo tanto el apoyo que pudiera dar nuestra Facultad de Ciencias Contables al Sector PYMES, al margen de las demás (Administración, Economía, Ingeniería Industrial, de Metalurgia, de Minas, de Sistemas, Derecho y Educación) sería insuficiente para atender en forma global y efectiva a un problema que tiene muchas aristas, como se ha venido analizando.

\section{COORDINANDO LAS ACTIVIDADES A NIVEL UNIVERSIDAD ENTRE TODOS LOS CEUPS}

Con el objeto de organizar una Unidad de Asesoria a PYMES, municipalidad y regiones a futuro, como proyecto piloto se deben dar los siguientes pasos, a nivel del Vicerrectorado Académico: 
1. Nombrar un Comité Coordinador integrado por un representante de las siguientes facultades, que sin ser excluyentes, todas las demás son complementarias: Administración, Contabilidad, Economia, Ingenieria Industrial, Ingenieria de Sistemas, Derecho y Educación.

2. Sobre la base del conocimiento de recursos disponibles, tanto humanos como materiales, se definiria las áreas de servicios a promocionar:

- Diagnóstico Empresarial:

Segmentos a servir: PYMES industriales, municipalidades y regiones en el futuro. Que consistiria en un análisis metódico de las empresas para identificar sus fortalezas y debilidades en la gestión y la producción.

3. Asistencia Técnica: Busca soluciones inmediatas a los problemas identificados en:

- Gestión Empresarial.

- Marketing y ventas.

- Administración, organización, costos.

- Elaboración de proyectos y perfiles de inversión.

4. Asesoria en Aspectos Productivos:

- Mejoramiento de la calidad.

- Mejora de procesos y métodos de trabajo.

- Distribución de planta, seguridad e higiene ambiental.

- Mantenimiento y reparación de máquinas $\mathrm{y}$ equipos.

- Instalaciones eléctricas, hidráulicas, neumáticas, y montaje de máquinas.
5. Capacitación: Cursos específicos, eminentemente prácticos y de corta duración, donde se utilice un lenguaje adecuado a los grupos, con horarios flexibles, según las necesidades del usuario. Los cursos que se podrian desarrollar son:

Calidad Total.

- Contabilidad

- Control Interno.

- Dirección de Empresas.

- Finanzas.

- Informática.

- Investigación de Mercados.

- Logistica.

- Planeamiento Estratégico.

- Producción.

- Recursos Humanos.

- Reingeniería de Procesos.

\section{Diplomaturas}

- A cargo de las Unidades de Postgrado.

6. Organizar una base de datos de todos los profesores expertos en capacidad de dictar cursos de especialización previamente propuestos por el Comité Coordinador.

7. Organizar seminarios y mesas redondas en forma itinerante por todas las Facultades integrantes del Comité Coordinador, a efectos de formar opinión en apoyo de las PYMES del sector manufacturero, con la presencia de sus directivos vendiendo la idea de servicio a que está dispuesta la Universidad. 
8. Establecer programas de prácticas preprofesionales para los alumnos de Pregrado de las Facultades integrantes del Comité Coordinador, formando bases de datos disponibles cuando ocurran las necesidades.

9. Buscar alianzas estratégicas con los directivos de las PYMES, con PROMPYME, con las ONGs interesadas en el tema capacitación aprovechando la imagen institucional de nuestra Universidad.

10. Si estas condiciones comienzan a dar sus frutos, en un lapso de dos años, y si el Proyecto resulta rentable, tomar la decisión de elevarla al nivel de una Dirección.

El financiamiento de este proyecto está a cargo de las Facultades que integren el Comité Coordinador, previa presentación del Presupuesto correspondiente.

\section{PROYECTO PILOTO DE ASESORÍA A PYMES, MUNICIPALIDADES Y REGIONES}

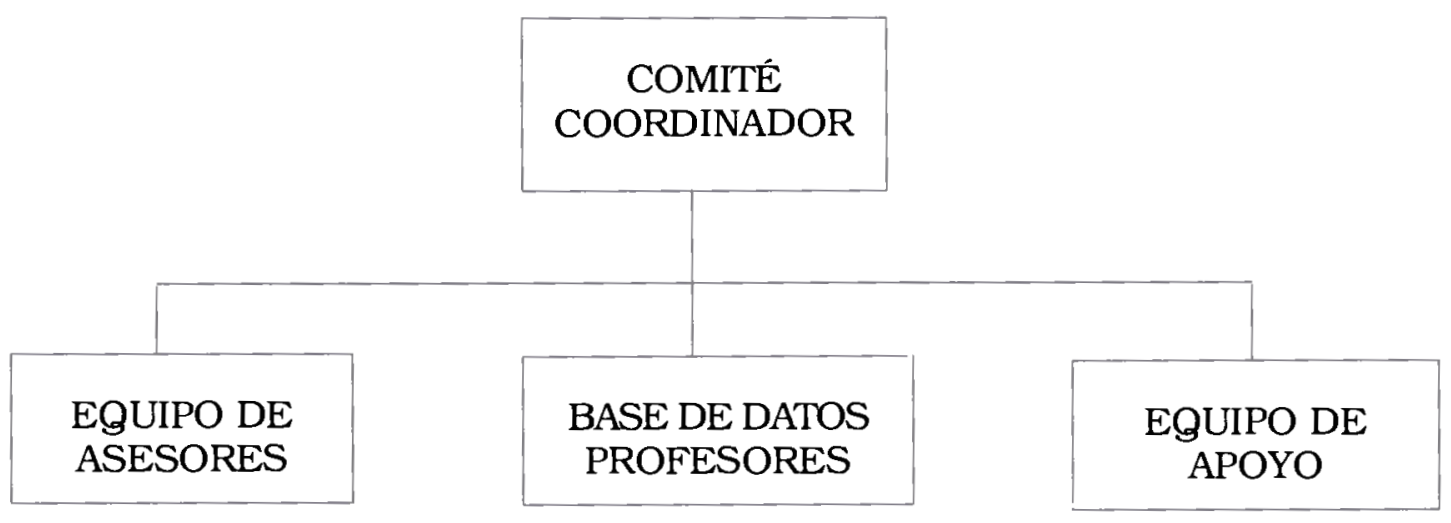

\section{CONCLUSIONES}

1. La Universidad Nacional Mayor de San Marcos para contribuir a unos de sus fines, como es la capacitación profesional, tiene la oportunidad de actuar como ente corporativo llevando a la práctica el proyecto que hemos denominado PROYECTO PILOTO DE ASESORÍA A PYMES, MUNICIPALIDADES Y REGIONES, presentando propuestas integrales en administración, contabilidad, economía, ingeniería industrial e ingeniería de sistemas, aporte polivalente como soporte educacional a la política de generación de empleo en estrecha relación con la realidad de las PYMES.

2. Permitirá desarrollar potencialidades dormidas de sus profesores expertos en estos temas, crear facilidades de prácticas preprofesionales a los alumnos de las diferentes facultades y contribuir al desarrollo económico del país en los sectores menos favorecidos.

3. Facilitará apuntalar las ventajas competitivas del Perú a fin de incrementar las exportaciones $y$ la generación de divisas. 
4. Contribuirá a mejorar la generación de ingresos de la Universidad vinculados directamente a una labor universitaria y extrauniversitaria.

5. Hará realidad el objetivo de "San Marcos Universidad Abierta" al servicio de los más pobres del país.

\section{BIBLIOGRAFÍA}

1. Aguilar Cruz, Jesús. Promoción de la Microempresa. Alternativa. Lima 1997.

2. Banco Central de Reserva del Perú. Agencia Interamericana de Desarrollo. Encuesta a PYMES de Lima Metropolitana. Lima, 1995.

3. Banco Interamericano de Desarrollo. Acceso a las Pequeñas y Medianas Empresas al Financiamiento. Washington D.C. Marzo 2002.

4. Centro de Investigaciones Sociales, Económicas y Tecnológicas. CINCEYT. Análisis de la Legislación PYME para un Marco Promotor. Lima, 1998.
5. Comité de la Pequeña Industria de la Sociedad Nacional de Industrias. Visión Estratégica para el Desarrollo y la Promoción de la Pequeña Empresa. Lima, 1997.

6. De Soto. Hernando. El Misterio del Capital. Noviembre 2000.

7. Ghersi, Enrique. La Economía Informal en América Latina. Cato Institute. Desarrollo Económico. www.elcato.org/economia-htm. Mayo del 2002.

8. Lam Álvarez, Juan Carlos. La Pequeña y Microempresa en el Perú. Visión Actual y Perspectivas Económicas. Comisión de PYME. Congreso de la República. Diciembre 1999, Lima.

9. Lanz Romero, José. Conferencias sobre la Pequeña Empresa. Una Sinfonía Inconclusa Editado por Norma Sánchez Bazalar de Lanz. Lima, 1997.

10. Luján, Juan Carlos. "El ATPA en la Red para todos». en El Comercio: Sección Económica (1 1 1.08.2002) Lima.

11. SENATI. http://www.senati.edu.pe (Footnotes) 